\title{
Out of sight, out of mind. Mental illness: who cares?*
}

\author{
PhiliP K. McGuIRE, Research Registrar, Institute of Psychiatry, De Crespigny Park, \\ London SE5 8AF
}

This conference approached the topical issue of the care of the mentally ill in the community and began by attempting to define the population of patients concerned. Opening the session, the chairman relayed the wry observation from Anthony Clare that none of the speakers invited to do this were actually psychiatrists. Undaunted, Roger Higgs, Professor of General Practice and Primary Care at King's College School of Medicine, pointed out that most psychiatric patients suffered from neurotic, rather than psychotic conditions, and were managed by GPs in the community rather than psychiatrists in hospitals.

An 'Opinions and Attitudes' session followed with David Boddy, of Market Research International, presenting the results of a survey of the attitudes of 100 Members of Parliament towards mental health. The great majority believed that mental illness was a growing problem (62\%), that the families of psychiatric patients did not receive adequate governmental support $(85 \%)$, and most $(56 \%)$ were against the closure of long-stay psychiatric hospitals. Remarkably, not a single MP believed that community care facilities for the mentally ill were good, $75 \%$ describing them as inadequate. Despite this, most rated action on mental health a lower priority than that on heart disease, cancer or health checks. An MP in the audience provided a possible explanation for this disparity from his constituency postbag; he had only received one letter on the topic of mental illness in the last eight years.

Ian Blair, Superintendent of the Kensington division of the Metropolitan Police, expressed concern at the increasing numbers of homeless patients his force were encountering, and emphasised that his officers were not trained in the management of the mentally ill. David Taylor, Chairman of

* The MSD Foundation Third Annual Symposium held at Queen Elizabeth II Conference Centre, 12 November 1990. the Lambeth, Southwark and Lewisham Family Practitioner Committee, sought to dispel the growing atmosphere of gloom, arguing that the quality of psychiatric care was now better than ever, and that increasing inter-professional liaison and greater understanding of the biological and sociological aspects of mental illness were grounds for optimism. In a session entitled 'When Caring Fails', Dr Peter Tyrer of St Charles Hospital, London, pointed out that three out of every four acute admissions were readmissions. He highlighted the problem of such 'revolving door' patients, suggesting that their care presented even more difficulties than that of patients relocated from institutions. He stressed the importance of psychiatrists operating in the community, using the hospital as a base, and the need for the training of community psychiatrists.

Opening the final session, the "Agenda for Success', Stephen Dorrell MP, the Parliamentary Under Secretary of State for Health, rather surprisingly began by praising Enoch Powell, an early proponent of the transfer of psychiatric care into the community. Mr Dorrell reaffirmed the Government's commitment to this policy and alluding to work by Professor Eve Johnstone and the Team for the Assessment of Psychiatric Services (TAPS), he suggested that this could be achieved without compromising patient care. Referring to the TAPS project, he added that the unit costs appeared to be lower for reprovided services. Perhaps in response to this, Sir Michael Drury, Professor of General Practice at the University of Birmingham, pointed out that community care should not be regarded as a cheap alternative to the institutional variety, and that adequate funding was essential. Closing the meeting, he argued that there was now sufficient knowledge available for the development of an effective community care service, with the next step being the application of that knowledge. 